\title{
The Child Health Conference
}

\author{
clientele \\ values \\ limitations
}

Analysis of the socioeconomic characteristics of families using the Long Beach Department of Public Health child health conferences and an evaluation of the conference functions and services.

\section{BY LONIS LIVERMAN, M.S.W.}

$\mathrm{C}$ HILD HEALTH SERVICES have received special attention throughout the world and more particularly in the United States within the last few years. This emphasis seems to result from the increasing awareness that "the biggest business in the world ... is the business of rearing children" (1).

Since the child health conference is one of the principal facilities through which child health services are provided, it has been the focus of much of this attention.

The child health conference, dating back to the early years of this century, covers a wide range of services-the traditional functions of periodic physical examinations, immunizations, and feeding instruction for the infant and preschool child and individual instruction for parents in the normal, physical, emotional, and social growth of the child as well.

In the conference, however, the continuity of medical care is broken because the child is cared

Mrs. Liverman is medical social work consultant to the Department of Public Health, Long Beach, Calif. for by one physician when he is well and another when he becomes ill. This is one of the criticisms of the conference $(\mathcal{Z})$.

Discussion has also centered on the nature of the services that should be provided $(3,4)$. And a difference of opinion has been expressed about the economic segment of the population that the child health conference should serve $(5,6)$.

The conference program provided since 1948 by the Long Beach Department of Public Health in California was studied to find answers to some of the questions that have been raised about child health conferences.

Information was sought on four areas related to conference services: $(a)$ the segment of the population served; $(b)$ the relationship of child health conference services to the medical care obtained for children; $(c)$ the benefits the families believe are derived from attendance; and $(d)$ the extent to which the parents' needs are met.

\section{The Long Beach Conferences}

The Long Beach Health Department program has expanded to seven conferences, each held 
weekly in the city's more heavily populated areas. The basic staff of each conference consists of 1 physician, $\supseteq$ public health nurses, and 2 or 3 volunteers recruited through the parentteacher association. The health department's psychiatrist and medical social worker are also arailable for consultation.

Services are provided without charge for children from birth to school age in families meeting the financial eligibility requirements. The frequency of the physical examinations. range from monthly for the infant to yearly for the healthy 4- or 5-year-old

Supplementary services are provided by the public health nurse. who extends conference care into the home. Ipon completion of the physical examination, the nurse reviews the physician's recommendations with the mother, making sure that they are understood and can be carried out. When conditions requiring treatment are discovered, the family is helped to find appropriate medical care. The mother may also use this opportunity to talk with the nurse about problems concerning herself, the child, or the family situation. When indicated, the nurse makes a followup home visit to talk further with the mother about problems raised during the discussion at the conference. The nurse adapts her health teaching to the needs and educational background of the family. She demonstrates procedures of child care and helps the mother to understand the child's growth and development, giving reassurance and emotional support to the mother in her handling of the child.

The public health nurse determines the family's eligibility for service. If the child is not under the care of a private physician and the family is unable to pay for health supervision under private auspices, a conference appointment is made. Financial eligibility is determined on a budget basis. Periodic evaluations ascertain continued eligibility. When income warrants, the family is helped to plan for health supervision under private auspices, and the children are discharged from the conference.

On April 1, 1952, 753 families were registered in the long Beach conferences. Of the 1,364 preschool children in these families, 1,213 had attended a conference.
The preschool children reached represent a roughly estimated 17 percent of the city's children potentially eligible on the basis of financial status alone. According to 1950 census figures, Long Beach has 23,163 preschool children, and 34 percent of the city's families have yearly incomes of less than $\$ 3,000(\%)$. Thus, allowing 1 preschool child to a family, at least 7,875 preschool children come from families living on $\$ 3,000$ a year or less. Actually, there are probably more because of the inverse ratio of number of children to size of family income $(8)$.

\section{Characteristics of the Study}

In the study, the records of the total conference population, 753 families, were reviewed, and 20 cases were selected at random for more intensive study involving an interview with a parent. Except for very low incomes and larger-than-average households, the families registered in the conferences appeared to be representative of families in the community. The characteristics of the sample families were compared with those of the total conference population with respect to racial distribution, household composition, housing, income distribution, and conference attendance. This comparison revealed close similarity in percentage distribution in all but two categories-housing and length of attendance.

Of the families interviewed, 42.2 percent lived in single unit houses, while only 32.6 percent of the total families had this type of housing. A greater difference was noted in the type of expenditure made for housing. In the sample group 31.6 percent were purchasing homes compared with 13.9 percent of the 753 families.

In length of attendance, 63.2 percent of the families interviewed had attended for more than one year, while only 48.9 percent of the whole group had used the conferences for this period of time.

It is recognized that use of percentages with reference to 20 cases, 2.6 percent of the total conference population, may be misleading. However, use of percentages allows a comparison of the characteristics of the sample families with those of the total families. Since the sample appears to be representative, some tenta- 
tive conclusions drawn from it may apply to the larger group as indications of areas in which further study is warranted.

\section{Population Segment Served}

Long Beach is an industrial community and a naval center. It has a population of approximately 251,000, weighted in the older age group and predominantly Caucasian. Eleven percent of the residents are 65 vears or over, and only 2.6 percent of the population is nonwhite $(y)$. While most of the families known to the conferences were white, an unusually large proportion, 27 percent, was nonwhite compared to the small nonwhite population in the city. This proportion was possibly influenced by the location of some conferences in Negro residential areas, by the special problems confronting Negroes in getting health supervision through private resources, and by the satisfaction Negro mothers got from conference services.

With few exceptions the conferences dealt with typical family groups. Of the total conference population, 606 families were composed of both parents and 1 to 3 children; 481 of these families were made up of the parents and 2 or more children. Conference families came from the city's low-income group, which was to be expected since there are financial eligibility limitations on attendance. Seventy-seven percent of the conference population had incomes of less than $\$ 3,000$ per year. Few families met the Bureau of Labor Statistics budget for a "modest but adequate" standard of living (9). Most of the families lived in low-rental areas. Slightly less than 80 percent lived in rented houses, and more than 40 percent of the families rented apartments in government housing projects.

Conference services appear to have been focused on the infant and young preschool child since 72 percent of the children registered in the conferences were under 3 years of age. Some questions are raised by this information. The years between the ages of 3 and 5 are recognized as one of the most important periods in a child's development and a taxing time for parents $(10,11)$. During this period parents may need considerable help in understanding their child and his growth patterns. One wonders then, why so few children in this age group were seen in these child health conferences. Is it because of lack of staff and facilities to meet the need? Or can it also be that conference personnel are still focusing on the traditional services of immunization, physical examination, and feeding instruction rather than gearing the services to provide guidance for parents in the social and emotional growth and development of their children as well?

If it is true that the conferences reached only 17 percent of the potentially eligible preschool children, one might ask why such a small percentage of those potentially in need actually received these services. Would this situation also be related to lack of staff and facilities to meet the need? Do people who could use the services know about the conferences? Can other ways of disseminating information about the conferences be discovered and used?

These are particularly significant questions in view of the limited sources of referral to conferences revealed in the interviews. More of the families learned of the services through friends and relatives than through any other source, although public health nurses and community agencies were other sources of referral. It was not the purpose of this study to answer these questions, but they appear to warrant further consideration.

\section{Relationship to Medical Care}

An attempt was made to obtain information that would be useful in evaluating whether the families saw supervision of the children's health as a part of their total medical care. In discussing the relationship of child health conference services to the medical care obtained for the children, only 1 of the 20 mothers interviewed mentioned an exchange of information between the conference and the facility giving sick baby care.

Nine of the mothers interviewed said they would prefer to consult the same physician for both medical care and health supervision. In spite of this fact, however, only four of these mothers said they would obtain health supervision through a private physician if they could afford to do so. Ten mothers expressed a pref- 
erence for child health conference care, cost notwithstanding. All 10 made statements which indicated that they were more comfortable in the conference setting, and 2 mothers also based their preference on the nature of the care. They believed that the conference staff gave them more time and had more personal interest in them than was true of the private practitioner's office.

The discussion about conference services revealed some possible reasons for this apparent contradiction. Only two of the families had ever obtained child health supervision privately, and both had been forced to discontinue for financial reasons. All of the mothers believed private health supervision to be out of their financial reach. Thus, it is reasonable to assume that there may have been an element of rationalization in their statements. On the other hand, they made it clear that the atmosphere of the conference was an important determining factor in their preference for this setting, and the services of the auxiliary personnel of the conferences were obviously of great importance to many mothers.

A less tangible factor that may be significant in influencing mothers' attitudes toward medical care is the difference in the emotional content of a well baby visit from that of a visit to a medical facility, where illness is the primary concern. Many people still associate a visit to the doctor's office with all of the fear, anxiety, and pain that it often means. Ordinarily none of these feelings is associated with a child health conference appointment. The mother is not only quite free of anxiety for her own child, but she is not likely to have her security threatened by another mother's worries as is often the case in a sick baby clinic or the physician's office.

There is no evidence that can be used in evaluating whether this view point is really a significant factor or how significant it might be in influencing attitudes toward medical care. It seems to warrant consideration, however, and if there is validity in this thinking, it might be well to consider adjustments in the ways in which health supervision is offered in private medical offices at this time. It might be possible to utilize some of the positive factors in child health conference services in private pediatric care.
Another, more immediate, need is pointed up here. Participants in the provision of child health services, including parents, agree that both health supervision and medical care would be more effective if they were not separated. One wonders, then, if they need be as dissociated as they are, even as they are provided now. Apparently there is need to evaluate the effectiveness of lines of communication between child health conferences and the facilities which provide medical treatment for children, including the offices of physicians in private practice. It might be possible to devise some method of unified recordkeeping. For example, the physician might be able to use the information in the baby book kept for the mother by conference personnel in order to fill gaps in his knowledge of the child's growth and development. He might, in turn, record significant medical findings in the same book for the use of conference personnel.

\section{Benefits Derived From Attendance}

As was to be expected, the traditional functions of the conference were among the first to be mentioned in discussing conference benefits. Almost all of the mothers interviewed gave the physical examinations and immunizations as important reasons for bringing their children to the conferences. Their comments revealed, however, that these services were important, not for themselves as much as for the reassurance and support they offered. Other studies have commented on this need for reassurance as a factor in conference attendance (12). There are several reasons why it is so important to mothers. Many young women are frightened at the responsibility of caring for a small baby. They feel uncertain about their ability to recognize and handle difficulties with the baby, and they cannot rely on guidance from their parents the way young people were formerly able to do. Concepts about child care have undergone many changes within the last half century. Young people can no longer trust the old familiar ways, and they are insecure with the new. Mothers stated these feelings in different ways. The following excerpt from one interview illustrates how one mother expressed it. 
Mrs. Victor said that the conference had been especially valuable to her in helping her to apply to her baby and the way he grows the knowledge she obtained from books and articles. She did not depend on conference staff for detailed instructions, but when the clinician assured her that it was all right to start feeding the baby a new kind of food, she felt able to plan variations in his diet. She said this was her first baby and she wanted to do things properly. She feels fairly capable of taking care of him, but she guessed she needed a little reassurance that she was doing all right and that there was nothing the matter with him. It gave her confidence when the doctor told her the baby was healthy, and confirmed her methods of caring for him.

All of the mothers interviewed expressed appreciation of the services given by conference personnel. It was apparent that they had confidence in the professional ability of the staff. But beyond this, the pleasant, friendly atmosphere of the conference was also of great importance to them. They sensed that this was a place where motherhood and children are held in high esteem, and they responded to this regard. The impartial, personal attention given each mother was important to all of them, but it had special significance for Negro mothers. All six of the Negro mothers interviewed mentioned, in particular, that they enjoyed their conference experience because they were so well received. They appeared to recognize and place value on the fact that here the measure of success and status was based on competence in rearing children, independent of race or financial or social position.

The services received from public health nurses were especially important to the mothers interviewed. They appreciated the nurses' extension of conference service into the home and accepted it as evidence of interest in them and their problems. Several young mothers with first babies commented in particular about the valuable guidance they received from the public health nurse. A warmth of feeling between the mother and the nurse was revealed in most instances. The following excerpt from an interview describes the way in which one mother was helped.

Mrs. Davidson's principal reason for attending the conference was because it reassured her to know that the baby was well. This meant that she was doing things right and not neglecting her baby. She also believed the immunizations were important, but not the most important services to her. She mentioned how pleased she was when the public health nurse called at her home after the baby was born. She had no idea that anyone outside her family would be interested in helping her with the baby.

Twelve of the mothers interviewed indicated that they enjoyed the group experience their conference appointments afforded them. Their comments revealed that the conference provided a setting conducive to thoughtful consideration of the children's problems and ways of meeting them. They indicated a desire and readiness for group counseling in the area of child rearing. A number of writers have suggested that group methods may be applicable and useful to supplement the usual child health conference services (13-15). Such counseling requires special knowledge and skill, however, and in the absence of trained group workers, it would seem important to provide training opportunities for staff members who indicate interest and ability to acquire these skills before undertaking such a program.

Criticisms of conference service were related primarily to the physical settings: crowding, confusion, and long waiting periods to see the clinician.

To make the services described here qualitative and satisfying to mothers, adequate staff and sufficient time to spend with each patient are necessary. It is the opinion of some that the experienced physician, working with known patients, should average 15 minutes per patient, particularly in the field of anticipatory guidance (16). It is equally important that other specialists working with the family, such as the public health nurse or medical social worker, also have sufficient time with each patient to make the contact a meaningful one.

\section{Needs of Parents in Child Rearing}

One purpose of this study was to evaluate the extent to which the parents' needs in the area of child rearing were being met. To discover the difficulties with which families believed they could use help, the interviewer described the social casework services provided in some child health conferences.

This problem-solving process provides methods of helping people understand what is caus- 
ing their problems and how to meet them. 'The caseworker helps the troubled person discover within himself, his family, and his community the resources necessary to deal with the difficulty confronting him. According to C'ockerill and others (1\%), the casework process involves three interrelated steps, study, diagnosis, and treatment, and is carried on in the light of certain guiding principles and with reference to knowledge of human behavior, social experience, and social institutions.

The mothers were asked if they could see value in having such help available. If so, they were asked to give examples of the ways in which they could use the service. Fourteen mothers said they would like this assistance and described how they would use it. Difficulties such as sibling jealousy, disciplinary problems, enuresis, and toilet training were cited.

There were also less specific problems with which mothers indicated a need for help. These included disagreement between the parents over the children, preparation of older children for the coming of a new baby, and differences between siblings in terms of behavior patterns and reactions-areas of service that are not unique to the field of social casework. The public health nurse also gives assistance with these problems. In any program in which the two professions, medical social work and public health nursing, work cooperatively it is essential that they plan together for the services that each will give. To be effective this planning must be based on mutual understanding of function (18).

The situations described by conference mothers, however, indicated a need for the special skills of the social caseworker. In some situations the caseworker's ability was needed to help parents understand and deal appropriately with a child's negativistic or aggressive behavior. In other instances her recognition of the danger of premature or inappropriate reassurance, as it may block the parent in revealing the real nature of the difficulty, was indicated. In nine cases the content of the interviews and the interviewer's observations in the home revealed social and emotional problems which the conference staff would not ordinarily deal with because the problems were not "within the normal range of parental difficul- ties" (15). Recognition of such problems requires trained and sensitive observation since they will often be concealed beneath superficially simple concerns.

Ideally, the needs described by the mothers interviewed would be met by the health department social worker. It is hoped that the day when this will be possible is not too far off. Realistically, few health departments have a sufficiently well-developed social service unit to extend these services on a complete coverage basis. Therefore, it is necessary to evaluate ways in which existing services can be used to meet the needs as fully as possible. By participating in the inservice training of conference personnel, the medical social worker could help sharpen their skills in recognizing social and emotional problems that should be referred to other sources of help and in assisting families to make use of such help. Existing social service units can also be consulted on ways in which to meet difficulties such as those described, and they can accept for service limited situations in which casework treatment is indicated and appropriate to the function of the conference.

\section{Other Implications of the Study}

Information obtained from the 753 conference records revealed a significant incidence of health problems among these families. Further study in this area seems indicated. It might be helpful to know the nature and extent of illness among the families attending child health conferences and the effect of illness on the family's economic status and on the emotional atmosphere in the home. In 9 of the 20 families interviewed relatively severe emotional problems were apparent. Two mothers expressed concern about the unfavorable effect their own behavior might be having on their children's behavior. One mother had a history of severe illness and radical surgery. At the time of the interview she was fearful of a recurrence of symptoms, but she had not sought medical attention. She realized that she was impatient and sharp with the children and that they responded with irritating and hyperactive behavior. The other of these two mothers gave a history of psychiatric hospitalization as a child. She appeared to be a tense and nervous 
person, and there was evidence of tension between her and the two older boys.

Two mothers gave evidence of being overanxious about their children. One was a young mother with her first baby born after 6 years of marriage. She voiced severe standards for the upbringing of her child, and the interviewer received the impression of frugal and rigid parents, apparently determined to provide what is best for their child but doing it sparingly, almost grudgingly. 'The other mother was 40 years old when her second child was born, and her first child was 12 years old at the time. The period prior to the baby's birth was an emotionally traumatic one, culminating in her separation from the baby's father. She had suffered a severe nervous reaction and was a tense and anxious-appearing person. She expressed many concerns about the baby and about her relationship with the older child.

One mother was concerned about whether the mental illness in her husband's family was hereditary. His mother and two sisters were in mental hospitals, and she expressed a need for help in knowing how to handle her daughter so that she would not contribute to the possibility of mental breakdown in her. One young mother believed her child's temper tantrums were due to the fact that she had "marked the child" prior to its birth. An unmarried mother was worried about the effect her situation would have on her son, and she wondered how and when she could explain it to him so that he would understand.

Two mothers described unsatisfactory relationships with their own parents, and in the discussions revealed how this was affecting their present parent-child relationships. One mother was deeply concerned about an older daughter who suffered from what she implied was a hereditary personality disorder. During one visit the interviewer could observe that the children were fearful of physical punishment from their mother, who seemed unduly strict with them. Even the 8-month-old boy put up his arms to shield his face when she spoke sharply to him. There were multiple problems in this family aggravated by conflict between the parents on how the children's difficulties should be dealt with.

It is difficult to evaluate whether this high incidence of emotional problems among the families interviewed indicates an interrelationship between economic stress and emotional upset in these families; whether there is more emotional distress among "average" families than is generally estimated $(8)$; or whether the conferences tend to attract anxious mothers who seek reassurance. In any event further study is indicated to determine the need and opportunity for a preventive mental health program.

One of the limitations of this study is that it has explored only the needs of those families who requested service and were able to meet financial eligibility requirements. It might be of interest to study the needs of families who requested scrvice and were found to be ineligible to learn whether they were able to get these services through other resources; and if not, what prevented them from providing the children with this necessary care.

\section{Summary}

The majority of the 753 families in the Long Beach Department of Public Health child health conferences came from the city's low-income group, lived in low-cost rental areas, and was made up of families composed of the parents and two or three children. Most of the families were white but a large percent were nonwhite compared to the small nonwhite population in the city. Most of the children, 72 percent, registered in the conferences were under 3 years of age, and only a small percentage of the families potentially eligible were utilizing the services.

Little cooperative exchange of information between child health conferences and facilities providing medical treatment for children was known to the mothers interviewed. Mothers recognized the disadvantages of this separation of services and expressed a desire for unification of child health supervision and medical care. Further study to improve lines of communication between conferences and treatment facilities seems indicated.

In discussing conference benefits the mothers interviewed almost invariably mentioned the physical examinations, immunizations, and feeding instruction as having importance for 
them. Their discussions, however, revealed that the reassurance these services offered was a more important factor in attendance than the services themselves. Mothers also mentioned the services of public health nurses as being especially valuable to them, and the pleasant, friendly atmosphere of the conferences was disclosed as a significant factor in conference attendance.

Fourteen of the mothers interviewed expressed a desire for social casework help. In describing how they would use it, difficulties, such as sibling rivalry, toilet training, and family conflicts were cited. It is recognized that public health nurses also give help with such problems, but those presented by the mothers were of such nature that the special skills of the social caseworker were indicated. Review of the 753 family records revealed a significant number of health problems among these families. The content of the interviews pointed up a high incidence of emotional distress among the families interviewed. Further study might bring clarification in this area.

Some changes in focus and staffing patterns appear necessary in order to meet the obliga-. tions incorporated in the newer concepts of child health supervision. Special training opportunities for conference staffs seem advisable so that services can be geared more toward providing guidance tor parents in dealing with "the normal, everyday problems in the growth and development of children" (19). The addition of medical social casework to conferences seems indicated, on a direct service basis when possible, and at least on a consultation level. The way is open to provide additional preventive mental health services and group counseling in the conferences when trained personnel are available to give these services. It is essential that the various professional disciplines who have a contribution to make to the health and welfare of children work together in providing their services.

It seems that in Long Beach, Calif., the child health conferences are meeting a community need, and expansion of the program is incicated to make the services available to more of the families who might be able to use them. It may be advisable to use new ways of disseminating information about conference care.

\section{REFERENCES}

(1) Chisholm, B. : A new look at child health. Washington, D. C., U. S. Government Printing Office, 1948, p. 7.

(2) Lichty, J. A.: Well child supervision. Rocky Mountain M. J. 48: 344-349 (1951).

(3) Wishik, S. M.: Current practices and trends in the child health conference. Am. J. Pub. Health 41: 57-65 (1951).

(4) Ginsburg, E. : Public health is people. New York, the Commonwealth Fund, 1950, pp. 86-103.

(5) Schlesinger, E. R.: Program planning for health supervision of the infant and preschool child. Albany, New York State Department of Health, 1950, p. 2.

(6) Smillie, W. G.: Public health administration in the United States. New York, the Macmillan Company, 1940, pp. 244-246.

(7) U. S. Bureau of the Census: United States census of population. 2. Characteristics of the population, 1950. California. Washington, D. C., U. S. Government Printing Office, 1952, pp. 5-83, 5-129.

(8) Dublin, L. I.: The facts of life from birth to death. New York, the Macmillan Company, 1951, pp. 22, 313.

(9) Family budget of the city worker, October, 1950. Monthly Labor Rev. 72 : 152-155 (1951).

(10) Josselyn, I.: Psychosocial development of children. New York, Family Service Association of America, 1948, p. 72.

(11) Midcentury White House Conference on Children and Youth: Healthy personality for every child : A digest of the fact finding report to the conference. Raleigh, N. C., Health Publications Institute, 1951, pp. 14-16.

(12) Foster, M. L.: Reasons for attending the child health station. Pub. Health Nursing 42: 123128 (1952).

(13) Fox, E. G.: Teamwork for the young child. Pub. Health Nursing 41: 187-191 (1949).

(14) Kris, M.: A group educational approach to child development. Techniques of helping children. New York, Family Service Association, 1949, pp. 1-8.

(15) Wishik, S. M. : Let's join hands for the good of children. Child 16: 123-126 (1952).

(16) Harper, P. A.: Better training in the care of the well child. Am. J. Pub. Health 40: 389-394 (1950).

(17) Cockerill, E. E., and others: A conceptual framework for social casework (a suggestive outline). Pittsburgh, University of Pittsburgh School of Social Work, 1952, pp. 7-8.

(18) Gilbert, R.: The public health nurse and her patient. Cambridge, Mass., Harvard University Press, 1951, pp. 316-323.

(19) Eliot, M. M. : New horizons for child health. Pub. Health Rep. 67 : 169-171 (1952). 